\title{
Three-Dimensional Computed Tomography of the Pulmonary Veins
}

\author{
HIROSHI TADA, M.D., HAKAN ORAL, M.D., BRADLEY P. KNIGHT, M.D., \\ and FRED MORADY, M.D.
}

From the Division of Cardiology, Department of Internal Medicine, University of Michigan Medical Center, Ann Arbor, Michigan

Computed tomography can be used to create highquality three-dimensional images. An example of a confluent left pulmonary vein in a patient with idiopathic paroxysmal atrial fibrillation is shown in the figure. The common trunk (arrows) and individual branches (arrowheads) are clearly seen. Thus, three-dimensional computed tomography of the heart may be useful for visualizing the pulmonary veins in patients with atrial fibrillation undergoing catheter ablation to isolate the pulmonary veins.

Supported in part by a grant from the Gunma Prefecture Government and by the Don Nouse Arrhythmia Research Fund.

J Cardiovasc Electrophysiol, Vol. 13, p. 521, May 2002.

Address for correspondence: Fred Morady, M.D., Division of Cardiology, Department of Internal Medicine, University of Michigan Medical Center, 1500 E. Medical Center Drive, B1F245, Ann Arbor, MI 48109-0022. Fax:

734-936-7026; E-mail: fmorady@ umich.edu

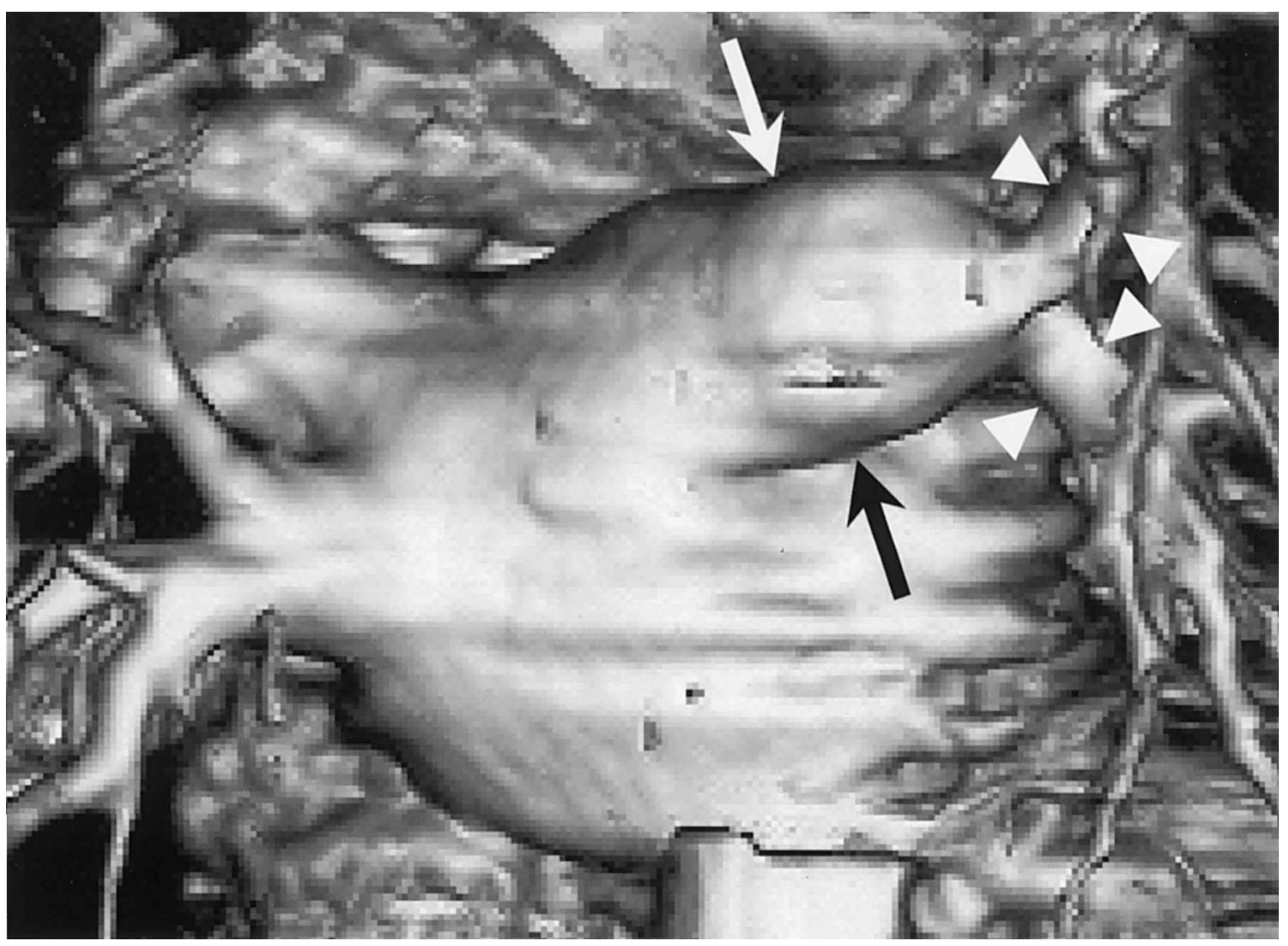

